\title{
A VACINAÇÄO NO CONTEÚDO DE LIVROS ESCOLARES
}

Camila de Menezes Succi*, Daniela Wickbold, Regina Célia de Menezes Succi

Trabalho realizado na Faculdade de Medicina do $A B C$ e Universidade Federal de São Paulo - Unifesp/EPM, São Paulo, SP.

RESUMO - Objetivo. Avaliar o conteúdo dos livros do ensino fundamental nos conceitos e nas informações que trazem sobre vacinação.

MÉtodos. Foram analisados 50 livros escolares da área de Ciências e Biologia por duas alunas do $5^{\circ}$ ano de medicina e por uma professora de medicina, na área de Pediatria, para verificar o seu conteúdo de vacinação.

Resultados. Dos 50 livros avaliados, 17 (34\%) não continham qualquer informação sobre vacinação. Dos 33 livros com informações sobre vacinas, $19(57,6 \%)$ continham informações incorretas: erros na definição de vacina, erro no calendário vacinal, desatualização de conteúdo, omissão de conteúdo e ilustração inadequada. Entre os erros, apontamos: citação de vacinas inexistentes (dengue) ou em desuso (varíola); o conceito de que vacina é um remédio; a indicação de vacinação apenas para crianças; associação de vacinas com dor e desconforto. Sobre o conteúdo vacinas, 26/33 (78,7\%) citavam conceito/definição de vacinas, 29/33 $(87,8 \%)$ associavam vacina com prevenção de doenças, 10/33 $(30,3 \%)$ citavam o calendário básico de vacinação e apenas $7 / 33$ $(21,2 \%)$ informavam sobre a vacinação de outras faixas etárias que não a pediátrica.

Conclusão. Apesar da importância do tema vacinação e das recomendações do MEC, mais da metade dos livros pesquisados apresentou alguma informação errada sobre 0 assunto.

UnIteRmos: Educação. Livros escolares. Vacinas. Ensino fundamental.

\section{INTRODUÇÃO}

Ao iniciar sua vida escolar, a criança traz consigo, oriundos da família, de outros grupos de relação mais direta ou da mídia, conceitos relativos à saúde, como higiene ambiental e alimentar, proteção contra acidentes e prevenção de doenças'

Considerando a educação como um dos fatores mais significativos para a promoção da saúde, devemos ressaltar a importância do ensino da criança, valorizando a influência do professor, assim como a utilização do livro didático, considerado o instrumento básico do trabalho pedagógico.

Sabe-se que o acesso à educação leva a melhores níveis de saúde e bem-estar, através da disseminação dos conhecimentos de higiene e das formas de prevenção das doenças. Promover a educação em saúde é um importante meio de possibilitar que a criança execute na prática as medidas de proteção à saúde que aprendeu na sala de aula. Além disso, as crianças se transformam em importantes

\footnotetext{
*Correspondência:

Av. Altino Arantes, 198/03

CEP: 04042-001 - São Paulo - SP

Fone: (11) 275-1901 / 9548-4293
}

agentes de saúde quando divulgam no meio familiar o que aprenderam na escola.

Desde o século passado, ainda que não se tivesse destinado um espaço específico para abordar a questão, os conteúdos relativos a saúde e doença foram sendo incorporados ao currículo escolar brasileiro. Entretanto, foi somente em 197| que a temática da saúde, sob a designação genérica de Programas de Saúde, foi formalmente introduzida no currículo escolar².

$A$ vacinação é um dos temas que deve ser desenvolvido no ensino fundamental, visto que se encontra entre as ações de natureza eminentemente protetora da saúde, juntamente com vigilância epidemiológica e sanitária!.

Desde 1995, o Ministério da Educação estabeleceu como uma das prioridades de ação o aprimoramento do livro didático. No entanto, ainda existem livros que contrariam tal determinação, por conterem erros conceituais e/ou informações equivocadas ou por veicularem noções preconceituosas e discriminatórias, apontando para a necessidade da avaliação qualitativa do livro didático ${ }^{3}$.

O objetivo deste trabalho foi avaliar o conteúdo dos livros didáticos do ensino fundamental nos conceitos e nas informações que trazem sobre vacinação.

\section{Métodos}

Duas alunas do $5^{\circ}$ ano médico de uma faculdade de São Paulo, e uma professora de medicina, na área de Pediatria, solicitaram a três grandes livrarias do município de São Paulo, no mês de abril de 2002, a lista de todos os livros didáticos disponíveis da ${ }^{\text {a }}$ a 8 a série, das áreas de Biologia e Ciências. Esta primeira busca tornou disponível 38 exemplares diferentes de livros didáticos na área de Ciências e Biologia.

Para aumentar a amostra, solicitamos a dois professores de Ciências do ensino fundamental do município de São Paulo que fornecessem os livros didáticos utilizados no ano de $200 \mathrm{I}$ em todas as séries do colégio onde lecionavam, sendo fornecidos 12 livros. Com essa busca totalizamos 50 livros didáticos de Biologia e Ciências, que podem ser vistos no anexo I.

Para cada livro foram analisados os seguintes itens:

- série escolar a que se destinavam;

- ano de edição;

- disponibilidade de edição mais recente;

- aprovação pelo Ministério da Educação (MEC);

- formação profissional dos autores;

- presença de informação sobre saúde;

- presença de informação sobre vacinas. 


\section{ANEXO I - LISTA DOS LIVROS ESCOLARES AVALIADOS}

\section{Ia SÉRIE:}

I. Aprendendo Ciências - Conteúdos essenciais para o Ensino Fundamental de la a 4a série. César Coll, Ana Teberosky. Editora Ática, 2000.

2. Rosa-dos-Ventos - Ciências Naturais. Emmanuel C Oliveira, Maria P Gonçalves. Editora Moderna, 2a edição, 1999.

3. Viva Vida - Ciências. Demétrio Gowdak, Pity Vassoler. Editora FTD. 1994.

4. De olho no futuro - Ciências. Marinez Meneghello. Quintento Editorial, 1996.

5. Viver e Aprender - Ciências. Elisabete C Trigo, Eurico M Trigo. Editora Saraiva, I0a edição, 2001.

6. Novo Tempo - Ciências Naturais; Anibal F F Neto, Maria I I Soncini, Simone P Martins. Editora Scipione, Ia edição. 1999.

7. Coleção Vitória-Régia - Ciências. Samuel R Lago, Erica Meirelles. Editora Lago-IBEP, 2000.

8. Projeto Presente - Ciências Naturais; Célia R Siqueira, Angela N Stempfer, Regina Averoldi. Editora Moderna, Ia edição. 2000.

\section{SÉRIE:}

I. Viva Vida - Ciências. Demétrio Gowdak, Pity Vassoler. Editora FTD. 1994.

2. Coleção Vitória-Régia - Ciências. Samuel R Lago, Erica Meirelles. Editora Lago-IBEP, 2a edição, 2001.

3. Projeto Presente - Ciências Naturais; Célia R Siqueira, Angela N Stempfer, Regina Averoldi. Editora Moderna, Ia edição. 2000.

4. Rosa-dos-Ventos - Ciências Naturais. Emmanuel C Oliveira, Maria P Gonçalves. Editora Moderna, 2a edição, 2000.

5. Novo Tempo - Ciências Naturais; Anibal F F Neto, Maria I I Soncini, Simone P Martins. Editora Scipione, I’ edição. 1999.

\section{3a SÉRIE:}

I. Viva Vida - Ciências. Demétrio Gowdk, Pitty Vassoler. Editora FTD, 1997.

2. Projeto Presente - Ciências Naturais. Célia R Siqueira, Angela N Stempfer, Regina Averoldi. Editora Moderna, Ia edição, 2001.

3. Rosa-dos-Ventos - Ciências Naturais. Emmanuel C Oliveira, Maria P Gonçalves. Editora Moderna, 2a ediçãa, 1998.

4. Coleção Vitória-Régia - Ciências. Samuel R Lago, Erica Meirelles. Editora Lago-IBEP, 2a edição, 2001.

\section{$4^{a}$ SÉRIE:}

I. Novo Tempo - Ciências Naturais; Anibal F F Neto, Maria I I Soncini, Simone P Martins. Editora Scipione, Ia edição. 1999.

2. Projeto Presente - Ciências Naturais; Célia R Siqueira, Angela N Stempfer, Regina Averoldi. Editora Moderna, Ia edição. 2000.

3. Viva Vida - Ciências. Demétrio Gowdak, Pity Vassoler. Editora FTD. 1994.

4. Rosa-dos-ventos - Ciências Naturais. Emmanuel C Oliveira, Maria P Gonçalves. Editora Moderna, 2a edição, 1998.

5. Coleçãa Vitória-Régia - Ciências. Samuel R Lago, Erica Meirelles. Editora Lago-IBEP, 1998.

6. Ciências - Eu e o Mundo. Jacob Keim. Editora FTD, I Ia edição, 1993.

\section{5a SÉRIE}

1. Ciências - Ar, Água e Solo. Ayrton C Marcondes, José C Sariego. Editora Scipione, 1996.

2. Ciências e educação ambiental - O meio ambiente. Daniel Cruz. Editora Ática, 33a edição, 2000.

3. Ciências - Entendendo a natureza - O mundo em que vivemos. César S Júnior, Sezar Sasson, Paulo S B Sanches. Editora Saraiva, I8a edição, 2001.

4. Vivendo Ciências. Maria L Luz, Magaly T Santos. Editora FTD, 1999.

5. Ciências - O meio ambiente. Carlos Barros, Wilson R Paulino. Editora Ática, 59a edição, 1997.

6. Ciências - Ambiente: ar, solo, água e ecologia, noções de astronomia. Albino Fonseca. Editora IBEP.

\section{6ª́ SÉRIE:}

I. Ciências - Seres Vivos. Ayrton C Marcondes, José C Sariego. Editora Scipione, 1996.

2. Ciências e educação ambiental - Os seres vivos. Daniel Cruz. Editora Ática, 30a edição, 2000.

3. Os Seres Vivos. Carlos Barros, Wilson R Paulino. Editora Ática, 65a edição, 2001.

4. Ecologia e Saúde - Os Seres Vivos - Proteção à Biodiversidade. José L Soares. Editora Moderna, $4^{a}$ edição, 1995.

5. Ciências - A Vida na Terra. Fernando Gewandsznajder. Editora Ática, Ia edição, 2000.

6. Vivendo Ciências. Maria L Luz, Magaly T Santos. Editora FTD, 1999.

7. Ciências - Entendendo a natureza - Os Seres Vivos no Ambiente. César S Júnior, Sezar Sasson, Paulo S B Sanches. Editora Saraiva, 18 a edição, 2001.

8. Aprendendo Ciências - Seres vivos, saúde e ecologia. Demétrio Gowdak, Neide S Mattos. Editora FTD, 199|.

9. Ciências - Seres Vivos. Albino Fonseca. Editora IBEP.

10. Ciências - Os Seres Vivos. Jenny L Marques, Dinorah P Porto. Editora Scipione, $4^{4}$ edição, 1997.

\section{$7^{\text {a }}$ SÉRIE:}

I. Aprendendo Ciências - Corpo humano, higiene e saúde, homem e ambiente. Demétrio Gowdak, Neide S Mattos. Editora FTD, 1991.

2. Ciências - Corpo Humano. Ayrton C Marcondes, José C Sariego. Editora Scipione, 1997.

3. Ciências e educação ambiental - Os seres vivos. Daniel Cruz. Editora Ática, 32a edição, 2000.

4. O Corpo Humano. Carlos Barros, Wilson R Paulino. Editora Ática, 64a edição, 2001.

5. Vivendo Ciências. Maria L Luz, Magaly T Santos. Editora FTD, 1999.

6. Ciências - Entendendo a natureza - O homem no ambiente. César S Júnior, Sezar Sasson, Paulo S B Sanches. Editora Saraiva, I8a edição, 2001.

\section{SÉRIE:}

1. Ciências - Química e Física. Ayrton C Marcondes, José C Sariego. Editora Scipione, 1996.

2. Vivendo Ciências. Maria L Luz, Sônia Salém, Carlos A M Ciscato. Editora FTD, 1999.

3. Ciências - Entendendo a Natureza - A Matéria e a Energia. César S Júnior, Sezar Sasson, Paulo S B Sanches. Editora Saraiva, I7a edição, 2001.

4. Ciências - Ambiente - Componentes e Interações. Paulo M Silva. Editora Nacional, 3a edição, 2001.

5. Ciências - Natureza e Vida - Matéria, Energia, Ecologia. Editora FTD, 1996. 


\begin{tabular}{|c|c|c|c|c|c|c|}
\hline Séries & $\begin{array}{c}\text { Ano de } \\
\text { publicação }\end{array}$ & $\begin{array}{l}N^{0} \text { de livros } \\
\text { analisados }\end{array}$ & $\begin{array}{l}\text { Informações } \\
\text { sobre saúde }\end{array}$ & $\mathbf{p}^{* *}$ & $\begin{array}{c}\text { Informações sobre } \\
\text { vacina }\end{array}$ & $\mathrm{p}^{*}$ \\
\hline $5^{\mathrm{a}}$ a $8^{\mathrm{a}}$ & $|99|-200 \mid$ & 27 & $24(88,9 \%)$ & & $20(80,0 \%)$ & \\
\hline
\end{tabular}

* Teste do Qui quadrado; ** Teste exato de Fisher

\begin{tabular}{|c|c|c|c|c|c|c|c|c|c|c|c|}
\hline $5^{\mathrm{a}} \mathrm{a} 8^{\mathrm{a}}$ & 20 & 10 & & 16 & & 4 & & 17 & & 3 & \\
\hline
\end{tabular}

* Teste do Qui quadrado; *** Teste exato de Fisher

Para os livros que continham o item "informação sobre vacinas", analisamos os seguintes aspectos:

- se a informação era correta ou não;

- se havia definição de vacina;

- se era citado ou mostrado o calendário vacinal e se este estava completo;

- se era citada a importância da vacina/vacinação na prevenção de doenças;

- se eram citadas vacinas para outras faixas etárias que não a pediátrica;

- quais vacinas foram citadas.

A análise dos livros foi feita pelas duas estudantes de medicina e os resultados foram colocados em tabelas específicas para cada série. A revisão da análise foi feita por uma profissional médica com experiência no assunto vacinação.

Para análise estatística dos resultados obtidos, foram aplicados testes estatísticos não paramétricos (Teste do Qui-quadrado e teste exato de Fisher). Foi considerada diferença estatisticamente significante aquela que apresentou p crítico menor que 0,05.

\section{Resultados}

Foram analisados 50 livros didáticos da área de Biologia e Ciências destinados ao ensino fundamental, sendo oito livros de ${ }^{a}$ série, cinco de $2^{a}$, quatro de $3^{a}$, seis de $4^{\mathrm{a}}$, seis de $5^{\mathrm{a}}$, dez de $6^{\mathrm{a}}$, seis de $7^{\mathrm{a}}$ e cinco de $8^{a}$ série.

O ano de edição variou de 199 | a 200 |, sendo que 32 livros (64\%) foram editados a partir de 1998 e somente 3 livros (6\%) foram editados há mais de 10 anos. Dos 50 livros, 42 (84\%) são a edição mais recente disponível e 2 (4\%) saíram de catálogo.

Quinze livros traziam o "logotipo" da aprovação pelo MEC e/ou faziam parte do Programa Nacional do Livro Didático (PNLD) e cinco livros traziam na capa que estavam de acordo com os Parâmetros Curriculares Nacionais (PCN).

Os autores dos livros possuem formação acadêmica variável, dividindo-se em ciências exatas (ex: professores de física), humanas (pedagogos) e biológicas (professores de biologia e ciências, médicos e professores de história natural). A maioria dos autores é professor de ciências e biologia (33), seguido por história natural (20), pedagogos (16) e professores do ensino fundamental ( 15$)$.

O conteúdo de saúde estava presente em 47 livros (94\%), sendo que os três livros sem esta informação eram de 8 a série.

Em relação à informação de vacina/vacinação, 33 livros (66\%) citavam este tema, sendo que em sete livros o tema foi citado em dois capítulos diferentes, totalizando 40 citações de discussão do assunto. Vacina/vacinação foi citada em capítulos específicos de vacinas 24 vezes e em outros capítulos 16 vezes (nestes, o assunto entrava apenas como informação da forma de prevenção de algumas doenças específicas).

A maior parte dos livros com conteúdo de vacinas $(19 / 33=57,6 \%)$ apresentava algum tipo de erro na informação, totalizando 25 erros nos 19 livros. As informações erradas foram divididas em: erro de conceito, incluindo erro na definição de vaci- na (oito), erro no calendário vacinal (oito), desatualização de conteúdo (cinco), omissão de conteúdo (três) e ilustração inadequada (uma). Entre os erros, apontamos: citação de vacinas inexistentes (dengue) ou em desuso (varíola); o conceito de que vacina é um remédio; a indicação de vacinação apenas para crianças; associação de vacinas com dor e desconforto.

A definição de vacina foi citada em 26 livros (78,7\%). A citação ou exibição do calendário de vacinação proposto pelo Ministério da Saúde ocorreu em 10 livros (30,3\%), e 29 livros $(87,8 \%)$ enfatizaram a importância da vacina como uma forma de prevenção de doenças. Apenas sete livros (21,2\%) citaram a existência de vacinas destinadas para outras faixas etárias diferentes da pediátrica.

As vacinas mais citadas foram: vacina contra a poliomielite (26 citações), contra a tuberculose (23 citações), contra o sarampo (2 I citações) e DPT ( 19 citações). Também foram citadas vacinas contra meningite (I 2 citações), dupla adulto (oito citações), tríplice viral (sete citações), hepatite B (sete citações), febre amarela (seis citações), anti-rábica (três citações), varíola (três citações), gripe, febre tifóide e varicela (duas citações cada), hepatite $A$, dengue e cólera (uma citação cada).

Para facilitar a análise das freqüências em que as informações ocorreram (sim ou não) e a proporção de erros registrada (informações corretas ou incorretas), separamos os livros em dois grupos: I a a $4^{\mathrm{a}}$ séries e $5^{\mathrm{a}}$ a $8^{\mathrm{a}}$ séries. Para verificar se havia diferenças entre 
essas proporções e freqüências, utilizamos o teste do Qui-quadrado e teste exato de Fisher. A análise revelou não haver diferença estatisticamente significante entre todas as variáveis analisadas (Tabelas | e 2).

\section{Discussão}

Segundo o resultado do Censo Escolar do ano de 200 I, divulgado pelo Ministério da Educação (MEC), o Brasil tem hoje cerca de 54 milhões de estudantes. Desse total, 35,2 milhões estão matriculados no ensino fundamental ${ }^{4}$.

Se considerarmos que todos estes estudantes utilizam livros didáticos no aprendizado, poderemos dizer que temos cerca de 54 milhões de potenciais "agentes da educação" divulgando o conteúdo, correto ou não, desses livros.

Preocupado em promover a melhoria da qualidade dos livros do ensino fundamental, o MEC iniciou em 1995 um projeto de avaliação desses livros. A partir dessa época, os livros revisados e recomendados pelo MEC passaram a fazer parte do Programa Nacional do Livro Didático (PNLD)3.

A preocupação em aproveitar a permanência na escola para transmitir conceitos úteis sobre educação em saúde está presente em outros países, sobretudo com o advento da Aids, quando crianças portadoras da síndrome passaram a conviver com crianças sadias e essa convivência transformou-se em instrumento de educaçãa ${ }^{5}$.

Assim, as autoras deste trabalho preocuparam-se em averiguar o que as crianças estavam aprendendo sobre saúde, em especial sobre vacinação, através da análise dos livros escolares do ensino fundamental. A pesquisa bibliográfica realizada sobre a revisão de livros do ensino fundamental em assuntos de saúde revelou apenas um site na internet/mídia eletrônica que tratava do assunto. Neste site, o autor (médico) relata a ocorrência de erros em livros de biologia e ciências não se detendo, entretanto, no assunto vacinas. Em 1994, o autor descreveu erros que variavam desde ortografia até condutas antiéticas ${ }^{6}$.

Em nosso trabalho, verificamos que a maioria dos livros com informação sobre vacinas (57,6\%) continha algum tipo de informação errada, mesmo edições publicadas nos últimos quatro anos ( 14 livros) e outras com aprovação do MEC/PNLD (cinco livros).
Livros cujos autores eram professores de biologia e ciências ou médicos também apresentaram erros sobre vacinas (nove livros).

Com o objetivo de propiciar aos sistemas de ensino, particularmente aos professores, subsídios à elaboração e/ou re-elaboração do currículo, o MEC estabeleceu Parâmetros Curriculares Nacionais (PCN). De acordo com esses parâmetros, o assunto vacinas é tratado da seguinte forma: os alunos de $\mathrm{I}^{\mathrm{a}}$ a $4^{\mathrm{a}}$ séries devem ter conhecimento do calendário vacinal e da sua própria situação vacinal, e reconhecer os principais sinais e sintomas das doenças transmissíveis mais comuns na realidade do aluno, formas de contágio, prevenção e tratamento precoce $e^{2}$; os alunos de $5^{\mathrm{a}}$ a $8^{\mathrm{a}}$ séries devem conhecer e utilizar formas de intervenção sobre os fatores desfavoráveis à saúde presentes na realidade em que vivem, agindo com responsabilidade em relação à sua saúde e à saúde coletiva e conhecer os recursos da comunidade voltados para a promoção, proteção e recuperação da saúde, em especial os serviços de saúde!.

Além de conhecer o calendário vacinal (inclusive as vacinas das faixas etárias que não a pediátrica) e a importância da vacina na prevenção de doenças, o aluno também deve conhecer enfaticamente a definição de vacina, para que não adquira conceitos equivocados, como "vacinas - um tratamento preventivo" ou "as vacinas são medicamentos", difundidos em alguns dos livros analisados.

Algumas vacinas em desuso ou inexistentes como vacina contra varíola, cólera, dengue e febre tifóide foram citadas em conjunto sete vezes, número igual ou superior às citações de vacinas de extrema importância como hepatite B (sete citações), raiva (três), gripe (duas) e hepatite A (uma).

Lembrando que crianças são bons agentes de saúde e que divulgam no ambiente familiar o que aprenderam na escola, os livros didáticos não deveriam deixar de informar sobre vacinas que possam ser úteis a todos os membros da família. Apenas sete livros $(21,2 \%)$ citaram a existência de vacinas destinadas para outras faixas etárias diferentes da pediátrica, como vacina contra gripe e difteria/tétano (dupla) adulto.

De acordo com o projeto de avaliação de livros didáticos do MEC, "as ilustrações são elementos de maior importância, devendo auxiliar a compreensão e enriquecer a leitura do texto, elas não deverão expressar, induzir a, ou reforçar preconceitos e estereótipos" ${ }^{\prime \prime}$. Assim, a associação de vacina com medo ou dor transmitida por uma ilustração de um dos livros avaliados em nosso estudo não devería ter sido publicada.

Acreditamos que os livros escolares do ensino fundamental perdem a oportunidade de introduzir conceitos corretos e adequados sobre vacinação, na época em que as crianças estão ávidas por novos conhecimentos e podem transmiti-los para seus familiares.

\section{Conclusóes}

Após avaliação do conteúdo dos livros didáticos do ensino fundamental nos conceitos e nas informações que traziam sobre vacinação, observamos que:

- apesar da importância do tema vacinação e das recomendações do MEC, 34\% dos livros didáticos do ensino fundamental não contemplaram este assunto;

- mais da metade dos livros pesquisados apresentou alguma informação errada sobre o assunto vacina/vacinação: erros de conceito, de calendário vacinal, desatualização ou omissão de conteúdo e ilustração inadequada;

- apesar da definição de vacina e sua importância na prevenção de doenças estar presente em mais de $78 \%$ dos livros analisados, aproximadamente a mesma porcentagem de livros omitiu informações como calendário vacinal e vacinas para faixas etárias diferentes da pediátrica;

- não houve diferença estatisticamente significante entre os livros de $l^{a}$ a $4^{a}$ séries e $5^{\mathrm{a}}$ a $8^{\mathrm{a}}$ séries em relação a todas as variáveis analisadas.

\section{Agradecimento}

Ao Laboratório Aventis Pasteur, que financioua aquisição dos livros.

\section{Conflito de interesse: não há.}

\section{SUMMARY}

Evaluation of SCHOOL-BOOKS CONTENT ON THE SUBJECT OF VACCINES

OBjeTICTIVES. Both school-books as well as teachers in elementary education play an important role in the dissemination of concepts on health education. 
To evaluate the content of the books used for elementary education with regard to their concepts and information on vaccination.

METHODs. A total of 50 schoolbooks in the domains of Sciences and Biology was analyzed to verify their content on vaccination. The work was carried out by two fifth year students of medicine and also by a professor in the area of Pediatrics.

Results. Of the 50 books analyzed, 17 (34\%) had no information whatsoever on vaccination. Regarding content, of the 33 books that did have information on vaccines, 19 (57.5\%) had incorrect information: errors on the definition of vaccines, errors on the vaccination calendar, absence of content updating, omission of the content and inadequate illustration. Among the errors are: mention of inexistent vaccines (dengue) or in disuse (smallpox), the fallacy that vaccine is a remedy, vaccine indication only for children and association of vaccines with pain and discomfort. Moreover, regarding content, 26 books (78.7\%) cited concept/definition of vaccines, 29/33 (87.8\%) associated vaccine with prevention of disease, 10/33 (30.3\%) cited a basic calendar of vaccination and only $7 / 33$ (21.2\%) informed on vaccination in other age brackets other than the pediatric one.

CONCLUSION. In spite of the importance of vaccination and notwithstanding the guidelines of MEC (Brazilian Education Ministry), more than half of the books analyzed had some misconception or wrong information on the subject. [Rev Assoc Med Bras 2005; 5 I (2): 75-9]

KEY wORDS: Education. Schoolbooks. Vaccines. Elementary education.

\section{RFERÊNCIAS}

I. Ministério da Educação. Ensino fundamental parâmetros e referências curriculares nacionais de $5^{\mathrm{a}}$ a $8^{\mathrm{a}}$ série [online] [citado 2 ago 2002]. Disponível em: http://www.mec.gov.br/sef/ estrut2/pcn/pdf/saúde.pdf.

2. Ministério da Educação. Ensino fundamental - parâmetros e referências curriculares nacionais de $\mathrm{I}^{\mathrm{a}}$ a $4^{\mathrm{a}}$ série [online] [citado 5 ago 2002]. Disponível em: http://www.mec.gov.br/sef/ estrut2/pcn/pdf/ivro092.pdf.

3. Ministério da Educação. Educação fundamental - avaliação de livros didáticos de $I^{\mathrm{a}}$ a $8^{\mathrm{a}}$ série. [online] [citado 5 ago 2002]. Disponível em: http://www.uol.com.br/folha/educacao/ ult305u923 I.shtml.

4. Ministério da Educação. Instituto Nacional de Estudos e Pesquisas - Censo escolar 2001. 200 I [online] [citado I set 2002]. Disponível em: http://www.inep.gov.br/censo/Escolar/ Sinopse/sinopse $2001 \mathrm{l}$ htm.

5. MMWR. Guidelines for effective school health education to prevent the spread of AIDS. MMWR Morb Mortal Wkly Rep 1988; 37(S2): 1 - 13.

6. Souza ESM. Erros de Ciências. 1994 [online] [citado 8 set 2002]. Disponível em: http:// euripedeshomepage.vilabol.uol.com.br/ erroscie.htm.

Artigo recebido: 06/1 I/03 Aceito para publicação: 26/I I/04

\section{Ante OBrasileira}

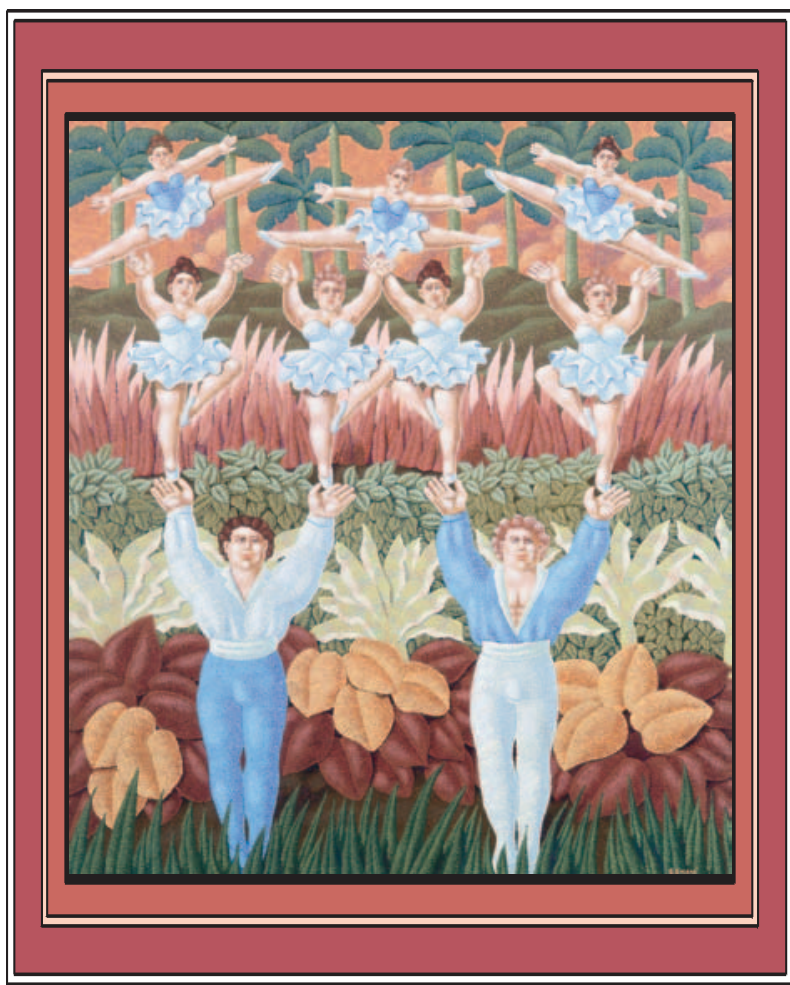

Ernanin Pavaneli - "Bailarinos" - Galeria Jacques Ardies - Tel.: (I I) 3884-29I6 